\title{
THE STRESS FIELD AT AN AXIAL ECCENTRICAL FATIGUE LOADING - INFLUENCED BY THE TEST TEMPERATURE
}

\author{
ROŞCA Vâlcu \\ Professor, Ph.D., Faculty of Mechanics/Department of Applied Mechanics and Civil Constructions, \\ University of Craiova, Craiova, Romania, rosca_valcu@yahoo.com \\ MIRIŢOIU Cosmin Mihai \\ Assistant, Ph.D, Faculty of Mechanics/Department of Applied Mechanics and Civil Constructions, \\ University of Craiova, Craiova, Romania, miritoiucosmin@yahoo.com
}

\begin{abstract}
By applying a cyclic eccentrically tensile loading, oscillatory positive, determines at the crack peak that exist in a plate specimen CT type a compound loading of bending with tensile. The aim of the study is to analyze the equivalent stress variation $\sigma$, when the working temperature varies, namely: $T=293 \mathrm{~K}\left(+20^{\circ} \mathrm{C}\right), T=253 \mathrm{~K}$ $(-20 \mathrm{C})$ and $\mathrm{T}=213 \mathrm{~K}\left(-60^{\circ} \mathrm{C}\right)$.

The specimens are made from a stainless steel 10TiNiCr175 type, and were loaded with the asymmetry coefficient $R=0.1$. There are drawn the variation curves of stress versus the crack length variation, $\sigma(a)$, versus the material durability, $\sigma(N)$, and respectively versus the stress intensity factor, $\sigma(\Delta K)$, for the three loading temperatures.
\end{abstract}

Key words: variable loading, asymmetry factor, stress intensity factor (SIF), loading temperature, loading stress

\section{Basic notions}

The stress concentration in a point or in a material area may lead to the crack initiation and then to its propagation. For a body (specimen) with side notch, cyclic loaded, the crack surfaces will have a relative displacement between them, after one of the three methods of crack propagation. The most met one is the first mode - through the crack opening, its ascension is made after a perpendicular direction on the crack front side.

It in the crack peak a trirectangular axes system Vxyz is attached, figure 1, the loading forces are toward the (y) direction, and the stress state is planar determined by the stresses: $\sigma_{\mathrm{x}}, \sigma_{\mathrm{y}}$ and $\tau_{\mathrm{xy}}$, figure 1 . A parameter is defined called "stress intensity factor" marked with $\mathrm{K}$, which depends simultaneously on the loading stresses and the crack geometry, proportional with the tensor $\sigma \sqrt{\pi a}$. In the Vxy plane, the polar coordinates $r$ and $\theta$ are established, figure 1 . The stresses that appear at the crack peak are determined with the relations (1), [1], [2], [4], [5], [8]:

$$
\left\{\begin{array}{l}
\sigma_{x}=\frac{K_{I}}{\sqrt{2 \pi r}} \cos \frac{\theta}{2}\left(1-\sin \frac{\theta}{2} \sin \frac{3 \theta}{2}\right) \\
\sigma_{y}=\frac{K_{I}}{\sqrt{2 \pi r}} \cos \frac{\theta}{2}\left(1+\sin \frac{\theta}{2} \sin \frac{3 \theta}{2}\right) \\
\tau_{x y}=\frac{K_{I}}{\sqrt{2 \pi r}} \sin \frac{\theta}{2} \cos \frac{\theta}{2} \cos \frac{3 \theta}{2}
\end{array}\right.
$$

For the planar stress state on the crack front, the principal normal stresses $\sigma_{1}$ are determined, respectively $\sigma_{2}$, [2], [6], [7], depending on $\sigma_{\mathrm{x}}, \sigma_{\mathrm{y}}$ and $\tau_{\mathrm{xy}}$ :

$$
\sigma_{1,2}=\frac{\sigma_{x}+\sigma_{y}}{2} \pm \sqrt{\left(\sigma_{x}-\sigma_{y}\right)^{2}+4 \tau_{x y}^{2}} \quad \text {, or [2], }
$$


ACTA UIVERSITATIS CIBINIENSIS - TECHNICAL SERIES

Vol. LXIX 2017

$$
\left\{\begin{array}{l}
\sigma_{1}=\frac{K_{I}}{\sqrt{2 \pi r}} \cos \frac{\theta}{2}\left(1+\sin \frac{\theta}{2}\right) \\
\sigma_{2}=\frac{K_{I}}{\sqrt{2 \pi r}} \cos \frac{\theta}{2}\left(1-\sin \frac{\theta}{2}\right)
\end{array}\right.
$$

These stress values can be determined during a fatigue loading by establishing some iterations for $\mathbf{r}$ vector and $\boldsymbol{\theta}$ angle, versus the crack front, figure 1 .
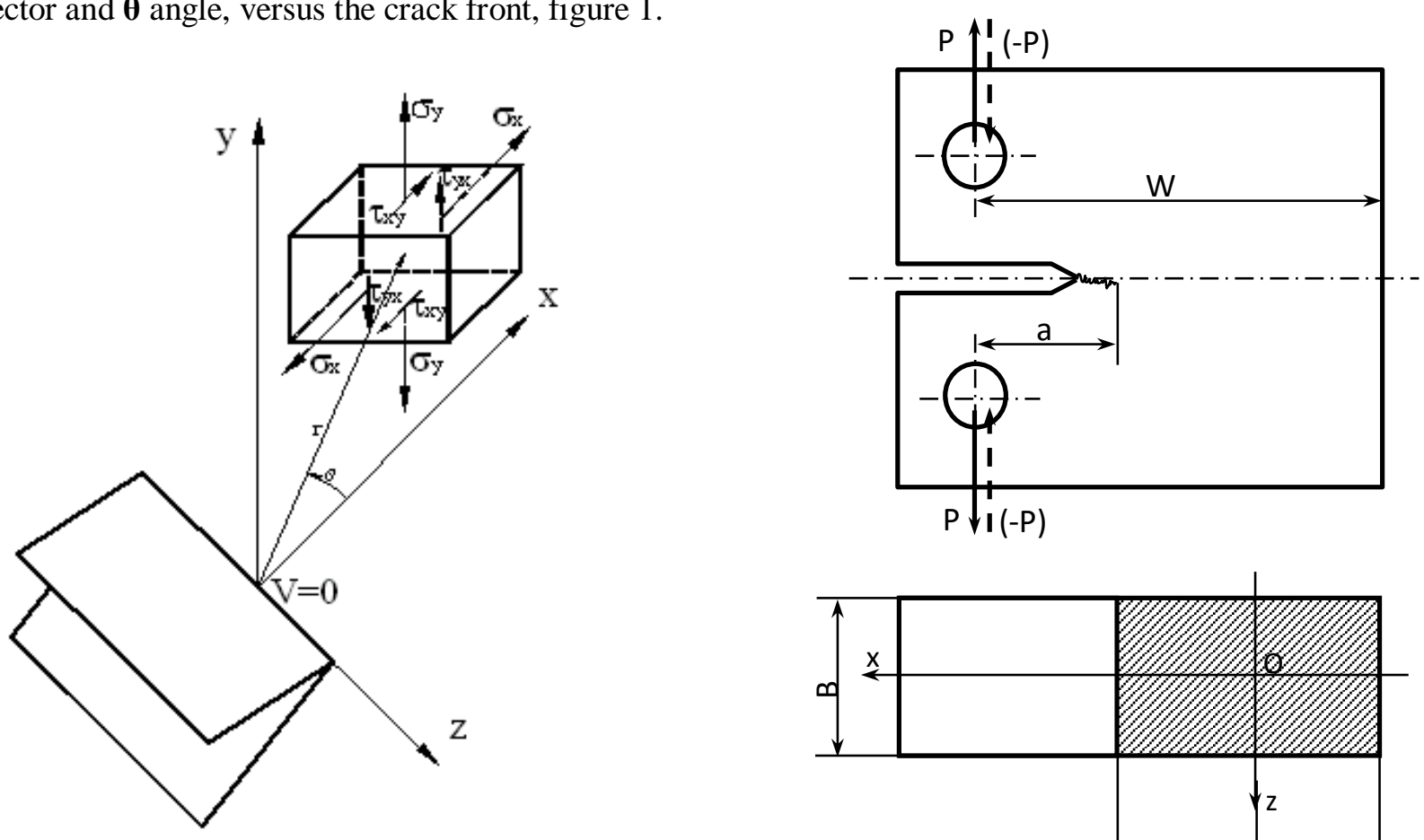

Figure 1: The stresses to top of the crack

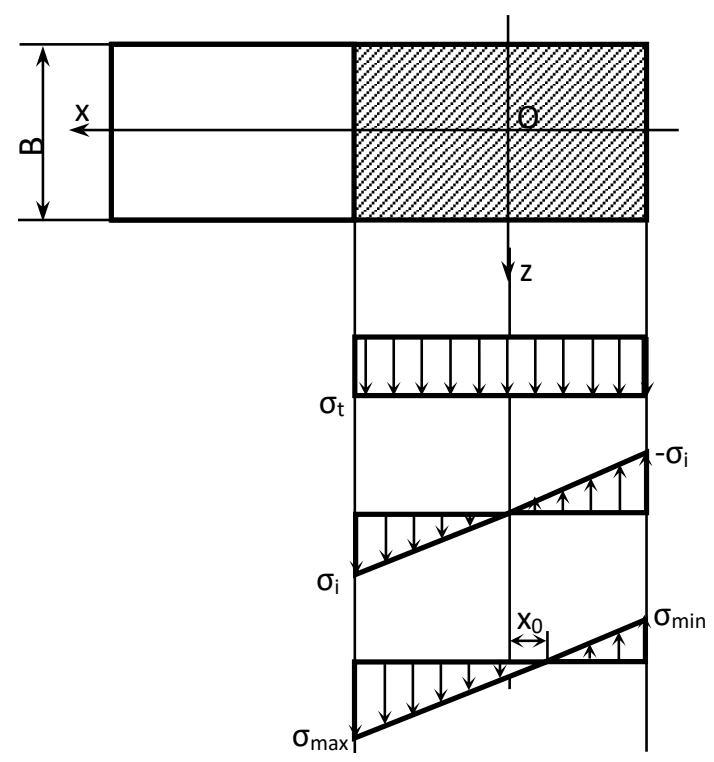

Figure 2.The specimen loading

\section{Experiments and obtained data}

For the experiments plate specimens were used, CT model, with side notch, figure 2, made from a stainless steel 10TiNiCr175 type, [5], [10]. These were subjected to a cyclic loading, axial - eccentrically, positive oscillatory type, with the asymmetry factor $\mathrm{R}=\sigma_{\min } / \sigma_{\max }=0.1$. Loading were made at the temperatures: $\mathrm{T}=293 \mathrm{~K}\left(+20^{\circ} \mathrm{C}\right), \mathrm{T}=253 \mathrm{~K}\left(-20^{\circ} \mathrm{C}\right)$ and $\mathrm{T}=213 \mathrm{~K}\left(-60^{\circ} \mathrm{C}\right)$. The testing machine was a hydraulic pulsatory device Shenck type, of $30 \mathrm{kN}$, with the working frequency of $5 \mathrm{~Hz}$. In the first stage, the specimens were pre-cracked with an initial crack length of $\mathrm{a}_{0}=2 \mathrm{~mm}$, for which the corresponding number of cycles $\mathrm{N}_{0}$ was retained. The crack length variation was followed with an optical microscope mounted on the testing machine, figure 3 . For the low temperatures $(253 \mathrm{~K}$ and $213 \mathrm{~K})$, on the machine, a 
cryogenic chamber was mounted [5], using petroleum ether as refrigeration environment, and nitrogen $\left(\mathrm{N}_{2} \mathrm{~L}\right)$ as cooling agent. In this case, the crack length a was determined by the elastic compliance method, using an extensometer with elastic lamellae mounted on the tested specimen [5].

After the pre-crack stage, there were retained the crack length variations $\underline{\mathbf{a}}_{\mathbf{i}}$, in gaps of $0.25 \mathrm{~mm}$, and the corresponding number of cycles $\mathbf{N}_{\mathrm{i}}$. In this way, there were highlighted primer experimental matrix data with $\left[\mathrm{a}_{\mathrm{i}}, \mathrm{N}_{\mathrm{i}}\right]$ type, necessary for the subsequent numerical processing.

For the beginning, the stress intensity factor is determined, for the cracking first mode, $\mathbf{K}_{\mathbf{I}}$, with the relation (4), on the experimental data domain $\mathbf{a}_{\mathbf{i}}$ :

$\Delta K=\frac{P_{\max }}{B \cdot \sqrt{W}} \cdot \frac{2+\frac{a}{W}}{\sqrt{\left(1-\frac{a}{W}\right)^{3}}} \cdot\left(-5,6 \cdot\left(\frac{a}{W}\right)^{4}+14,72 \cdot\left(\frac{a}{W}\right)^{3}-13,32 \cdot\left(\frac{a}{W}\right)^{2}+4,64 \cdot\left(\frac{a}{W}\right)+0,886\right)(5)$

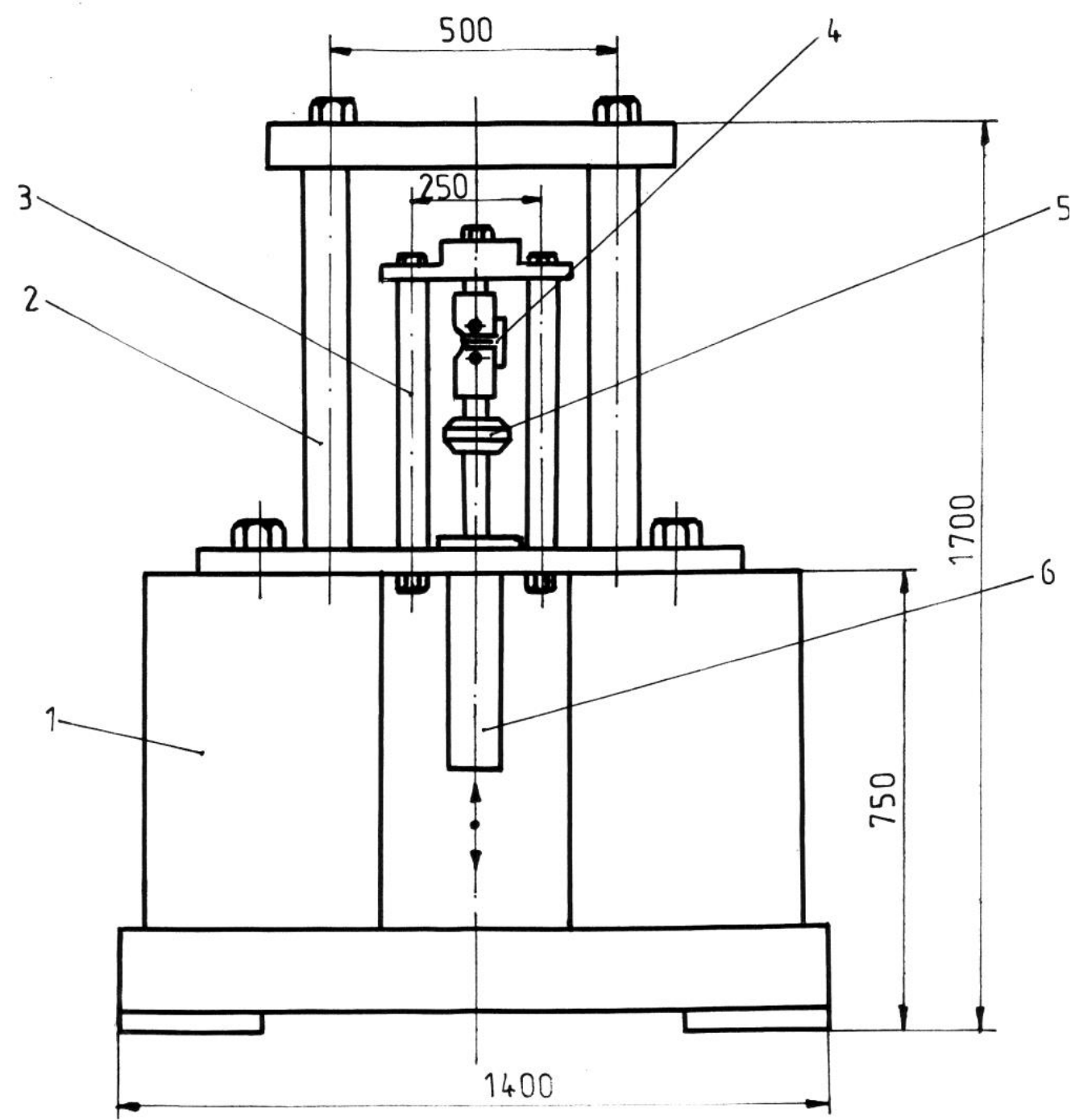

Figure 3. The testing device

The quantities from the above relation have the next specifications:

- $\mathrm{P}_{\max }$ is the maximum loading for the chosen cycle, in this case $\mathrm{P}_{\max }=6075 \mathrm{~N}$;

- $\quad \mathrm{B}$ - the specimen thickness, in $\mathrm{mm}$; 


\section{ACTA UIVERSITATIS CIBINIENSIS - TECHNICAL SERIES}

DOI: 10.1515/aucts-2017-0005

Vol. LXIX 2017

- $\quad \mathrm{W}$ - the active specimen width, in mm, figure 2;

- $\quad \mathrm{a} / \mathrm{W}$, is the crack normalized length, with fulfilling the condition $0.8 \geq \mathrm{a} / \mathrm{W} \geq 0.2$.

\section{The stress state analysis at the crack peak}

For each $\mathbf{a}_{\mathbf{i}}$ crack length, the stress intensity factor $\mathbf{K}_{\mathbf{I}}$ will be determined. In the $\left[\mathbf{a}_{\mathbf{i}}, \mathrm{a}_{\mathbf{i}+1}\right)$ domain, for the $\mathbf{r}$ vector but also for the $\boldsymbol{\theta}$ angle, some iterations are imposed and the stresses at the crack peak are determined: $\boldsymbol{\sigma}_{\mathbf{x}}, \boldsymbol{\sigma}_{\mathbf{y}}$ and $\boldsymbol{\tau}_{\mathbf{x y}}$, respectively the main stresses $\boldsymbol{\sigma}_{1}$ and $\boldsymbol{\sigma}_{2}$, with the relations (1), (2) or (3). Finally, for this gap, the maximum values of the stresses are determined: $\boldsymbol{\sigma}_{\mathbf{x}, \max }, \boldsymbol{\sigma}_{\mathbf{y}, \max }$ and $\boldsymbol{\sigma}_{1, \max }$.

By referring to the specimen loading, we assume that it is simultaneously subjected to a tensile loading with the axial force $\mathrm{N}=\mathrm{P}$ and bending toward the $\mathrm{Vz}$ axis with the bending moment $\mathrm{M}_{\mathrm{i}}=0,5 \mathrm{P}(\mathrm{W}+\mathrm{a})$, figure 2 . The loading stresses will be:

$$
\begin{aligned}
& \sigma_{i}=\frac{M_{i, z} \cdot x}{I_{z}}=\frac{P \cdot \frac{W+a}{2} \cdot x}{\frac{B \cdot(W-a)^{3}}{12}}=\frac{6 P \cdot(W+a)}{B \cdot(W-a)^{3}} \cdot x \\
& \sigma_{t}=\frac{N}{A_{e f}}=\frac{P}{B \cdot(W-a)}
\end{aligned}
$$

The resulting total stress will be the sum of the two individual ones, meaning:

$$
\sigma=\sigma_{t}+\sigma_{i}=\frac{P}{W \cdot(W-a)^{3}} \cdot\left[(W-a)^{2}+6 \cdot(W+a) \cdot x\right]
$$

and linearly varies, figure 2 .

The axes system attached to the crack Oxyz, figure 2, has origin $\mathrm{O}$ mobile, being at the middle of the raw section. In this contect, at the crack peak, for $\mathrm{x}=(\mathrm{W}-\mathrm{a}) / 2$, the maximum resulting stress will be:

$$
\sigma_{\max }=\sigma_{c}=\frac{2 \cdot P \cdot(2 \cdot W+a)}{B \cdot(W-a)^{2}}
$$

On a loading cycle duration, at its superior limit, for $\mathrm{P}=\mathrm{P}_{\max }$, the stress field will be:

$$
\mathrm{T}_{\sigma}=\left\lfloor\sigma_{x, \text { max }}, \sigma_{y, \text { max }}, \sigma_{1, \text { max }}, \sigma_{c, \text { max }}\right\rfloor
$$

\section{Graphic processing and conclusions}

Based on the methodology presented above, with the obtained experimental data, respectively with the ones numerically processed the next graphics are drawn:

- the maximum stress variation: $\sigma_{\mathrm{x}, \max }, \sigma_{\mathrm{y}, \max }, \sigma_{1, \max }$ and $\sigma_{\mathrm{c}, \max }$ versus the crack length variation_a, for the temperature $\mathrm{T}=293 \mathrm{~K}, \mathrm{R}=0.1$, figure 4 ;

- the maximum stress variation: $\sigma_{x}, \max , \sigma_{y, \max }, \sigma_{1, \max }$ and $\sigma_{c, \max }$ versus the stress intensity factor variation $\Delta \mathrm{K}$, for the temperature $\mathrm{T}=293 \mathrm{~K}$ and the asymmetry factor $\mathrm{R}=0.1$, figure 5 ;

- the same graphic types were obtained for the $\mathrm{T}=253 \mathrm{~K}$ temperature, figure 6 and figure 7 , respectively for the $\mathrm{T}=213 \mathrm{~K}$, figure 8 and figure 9;

- finally, on the same drawing, for the temperatures $\mathrm{T}=293 \mathrm{~K}, \mathrm{~T}=253 \mathrm{~K}, \mathrm{~T}=213 \mathrm{~K}$ the resulting 


\section{ACTA UIVERSITATIS CIBINIENSIS - TECHNICAL SERIES}

DOI: 10.1515/aucts-2017-0005

Vol. LXIX 2017

stress variation curves were drawn, for the compound loading of tensile and bending, $\sigma_{\mathrm{c}}$ versus the crack length variation $\left(\sigma_{c}(a)\right)$, figure 10 , respectively $\sigma_{c}$ versus the stress intensity factor variation $\left(\sigma_{c}(\Delta K)\right)$, figure 11 .

By analyzing the graphics from figures $4 \ldots 11$, we can highlight some conclusions:

- in all the figures, from 4 to 9 , for the whole loading temperatures, it is observed that the stress $\sigma_{c}$ at the compound loading is higher than the $\sigma_{\mathrm{y}}$, which effectively determined the crack spread, but is inferior ,as a value, to the normal main stress $\sigma_{1}$. This aspect is valid for the crack length variation a but also for the stress intensity factor $\Delta \mathrm{K}$. For the breaking domain of stable crack propagation, followed during the tests, the normal principal stress $\sigma_{1}$ varies between $220 \mathrm{~N} / \mathrm{mm}^{2}$ and $670 \mathrm{~N} / \mathrm{mm}^{2}$ for $\mathrm{T}=293 \mathrm{~K}$, figure 4 , between $270 \mathrm{~N} / \mathrm{mm}^{2}$ and $650 \mathrm{~N} / \mathrm{mm}^{2}$ for $\mathrm{T}=253 \mathrm{~K}$, figure 6 , respectively between $260 \mathrm{~N} / \mathrm{mm}^{2}$ and $600 \mathrm{~N} / \mathrm{mm}^{2}$ for T= $213 \mathrm{~K}$, figure 8 . In the same contect, the stress intensity factor $\Delta \mathrm{K}$ is between $670 \mathrm{Nmm}^{-3 / 2}$ and $1570 \mathrm{Nmm}^{-}$ ${ }^{3 / 2}$, for the temperature $\mathrm{T}=293 \mathrm{~K}$, figure 5 , and between $810 \mathrm{Nmm}^{-3 / 2}$ and $1590 \mathrm{Nmm}^{-3 / 2}$, for the temperature $\mathrm{T}=253 \mathrm{~K}$, figure 7 , and for the temperature $\mathrm{T}=213 \mathrm{~K}, \Delta \mathrm{K}$ varies between $800 \mathrm{Nmm}^{-3 / 2}$ and $1520 \mathrm{Nmm}^{-3 / 2}$, figure 9. We also remark that for the maximum loading stress at the crack peak $\sigma_{1}\left(\right.$ or $\sigma_{c}$ ), but also for the stress intensity factor $\Delta K$, there are no significant values variations for the loading temperature variation, which is not the same for the loading asymmetry factor variation $\mathrm{R}$.

- by referring to the figure 10 and figure 11 respectively, there is observed that for the same crack length variation $\mathbf{a}$, the stress at the peak crack $\boldsymbol{\sigma}_{\mathbf{c}}$ increases with the temperature decrease, figure 10 , inverse aspect for the stress intensity factor, figure 11. In the same reference, for the same loading stress $\boldsymbol{\sigma}_{\mathbf{c}}$, the stress intensity factor $\Delta \mathbf{K}$ will increase when the environment temperature decrease.

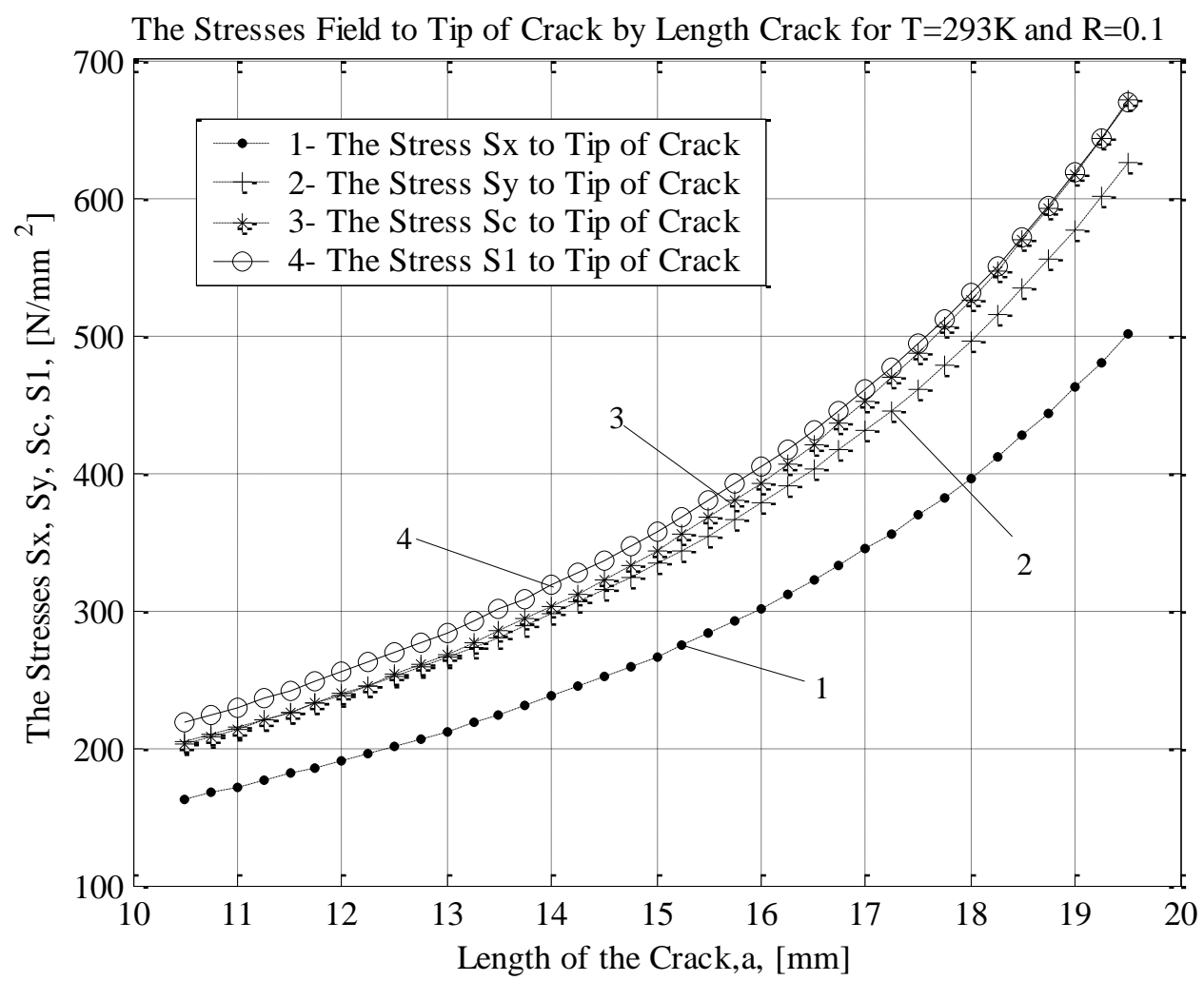

Figure 4: The stresses field to tip of crack by length crack for $T=293 \mathrm{~K}$ and $\mathrm{R}=\mathbf{0 . 1}$ 
ACTA UIVERSITATIS CIBINIENSIS - TECHNICAL SERIES

DOI: 10.1515/aucts-2017-0005 Vol. LXIX 2017

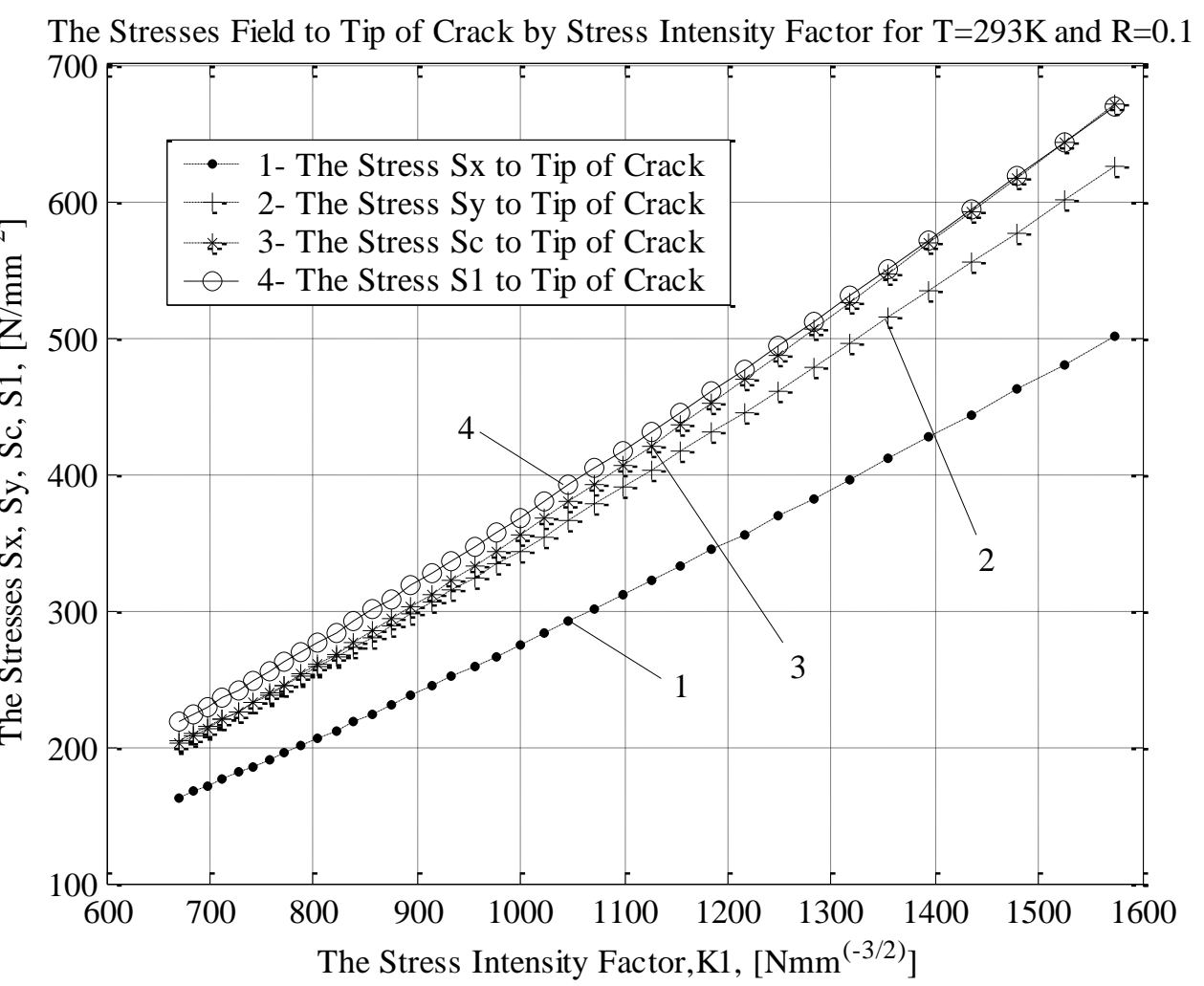

Figure 5: The stresses field to tip of crack by stress intensity factor for $T=293 \mathrm{~K}$ and $\mathrm{R}=\mathbf{0 . 1}$

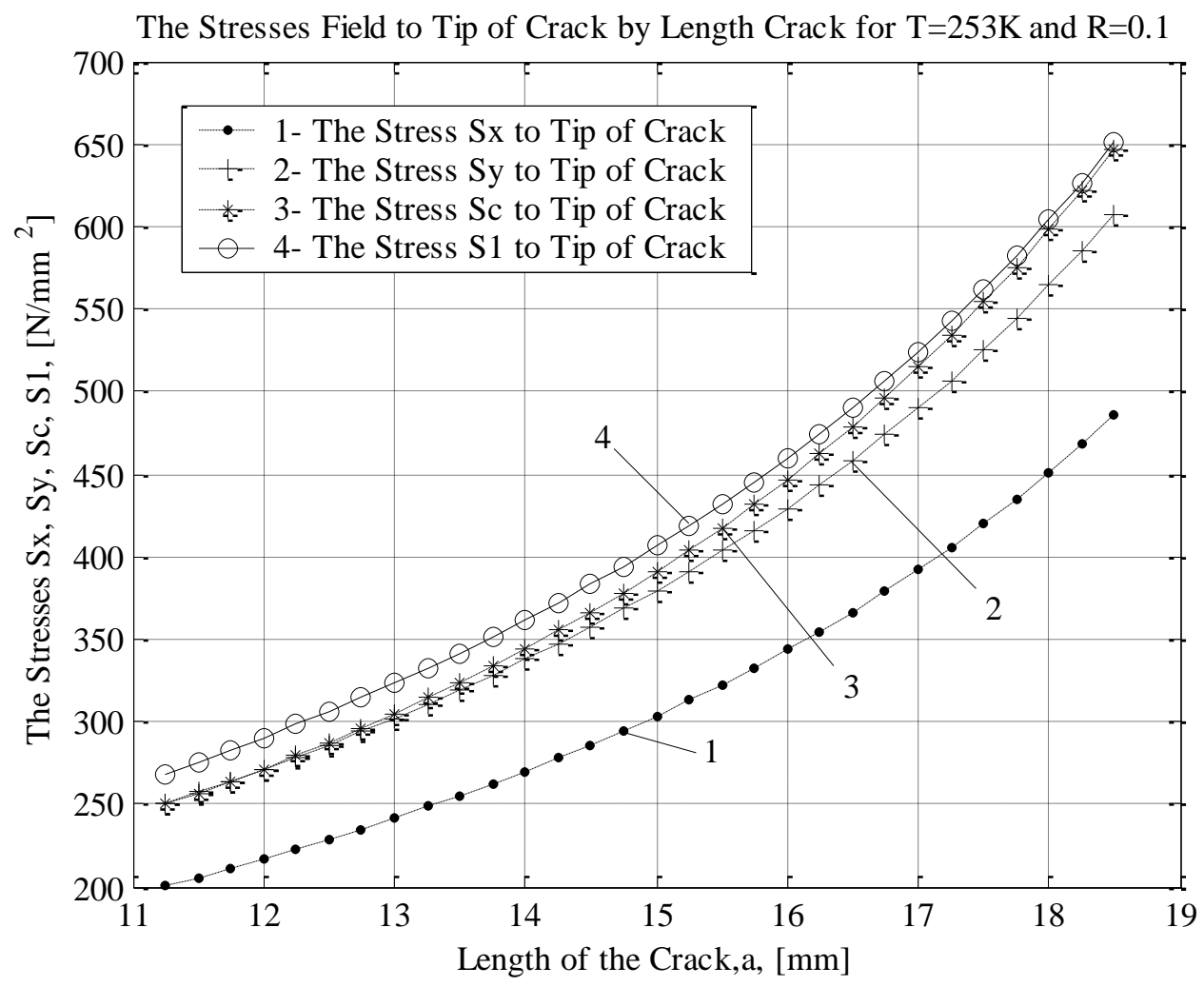

Figure 6: $T$ The stresses field to tip of crack by length crack for $T=253 \mathrm{~K}$ and $\mathrm{R}=0.1$ 
ACTA UIVERSITATIS CIBINIENSIS - TECHNICAL SERIES

DOI: 10.1515/aucts-2017-0005 Vol. LXIX 2017

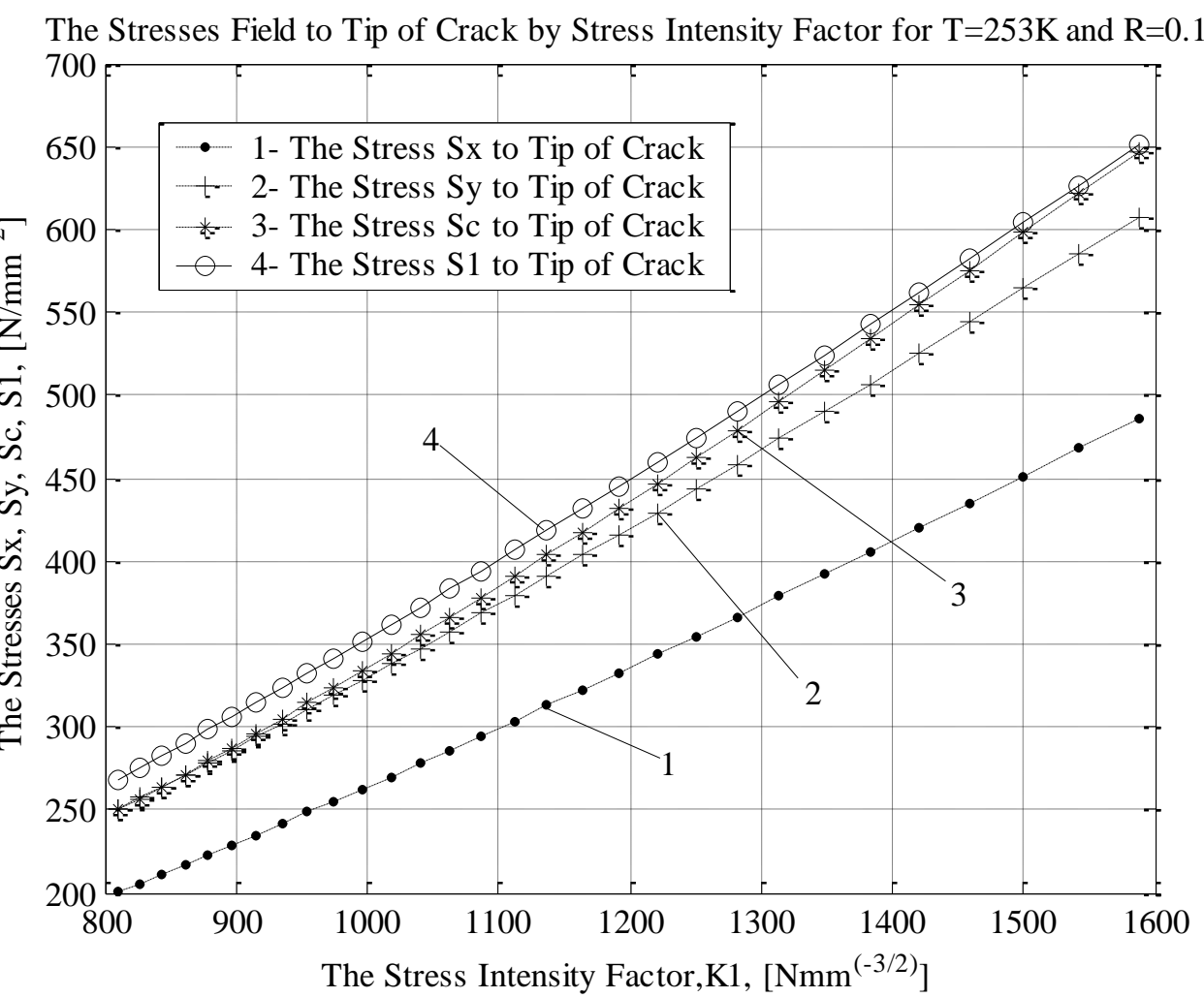

Figure 7: The stresses field to tip of crack by stress intensity factor for $T=253 \mathrm{~K}$ and $\mathrm{R}=0.1$

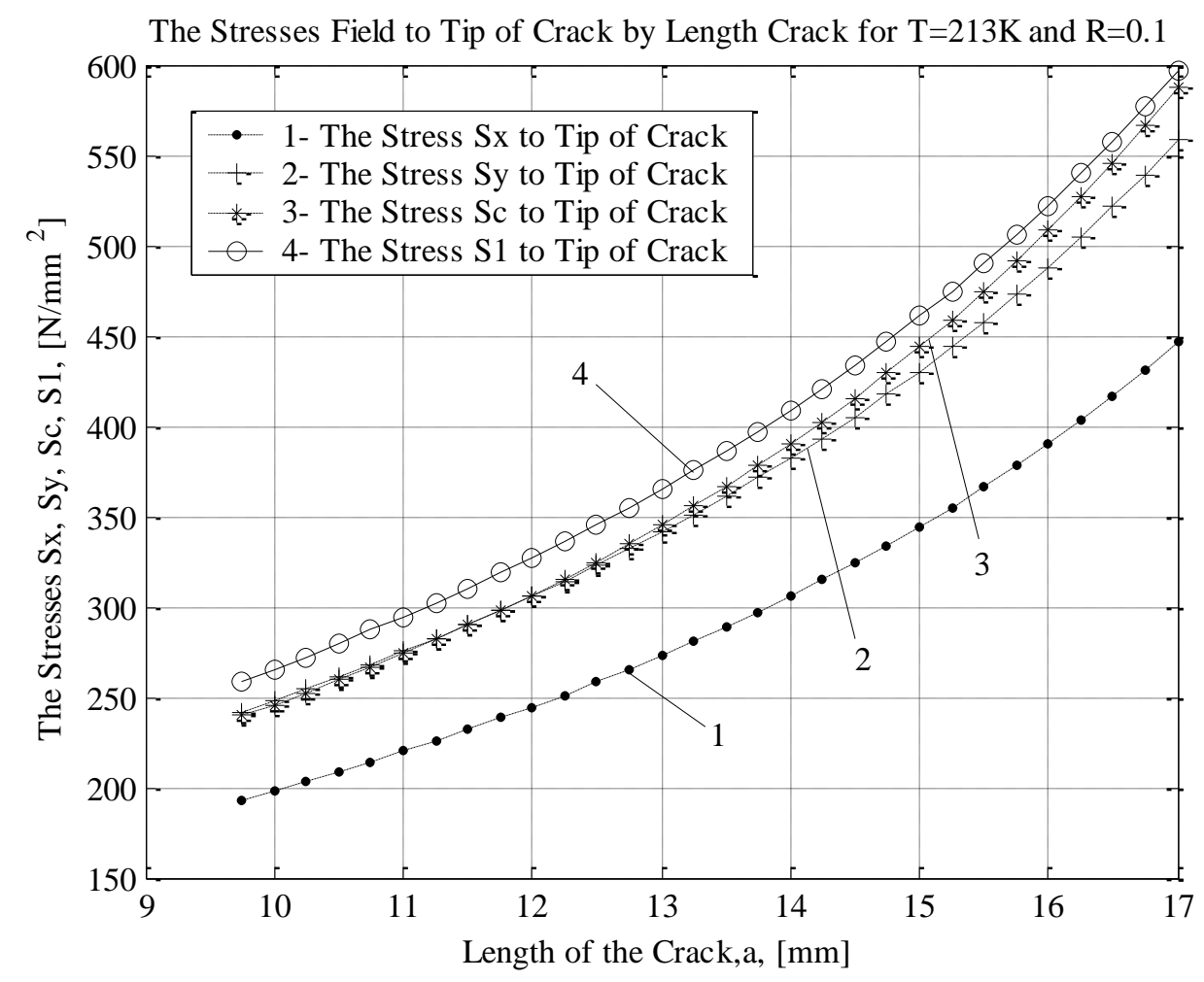

Figure 8: The stresses field to tip of crack by length crack for $T=213 \mathrm{~K}$ and $\mathrm{R}=0.1$ 
ACTA UIVERSITATIS CIBINIENSIS - TECHNICAL SERIES

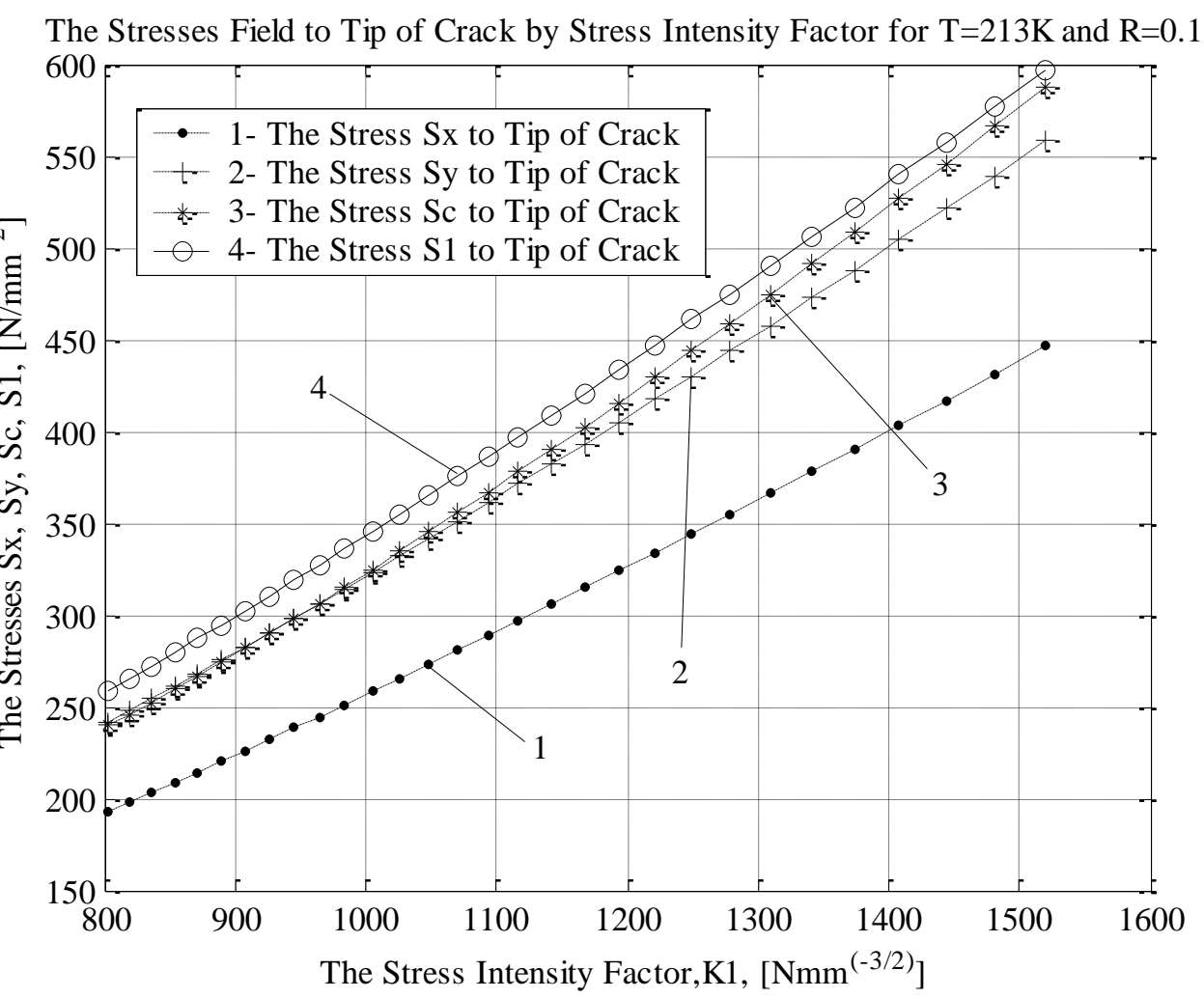

Figure 9: The stresses field to tip of crack by stress intensity factor for $T=213 K$ and $R=0.1$

The stress Sc versus length of crack

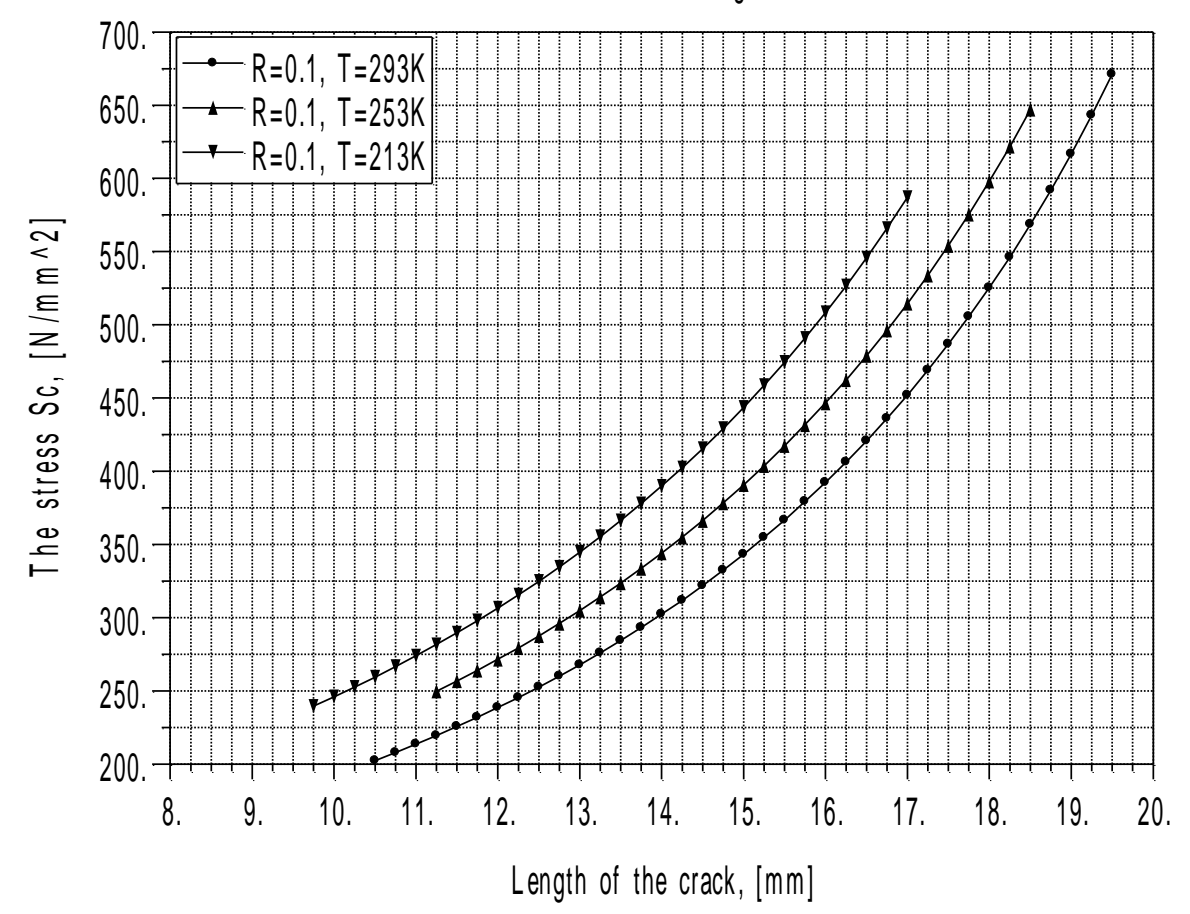

Figure 10: The stress Sc versus length of crack 


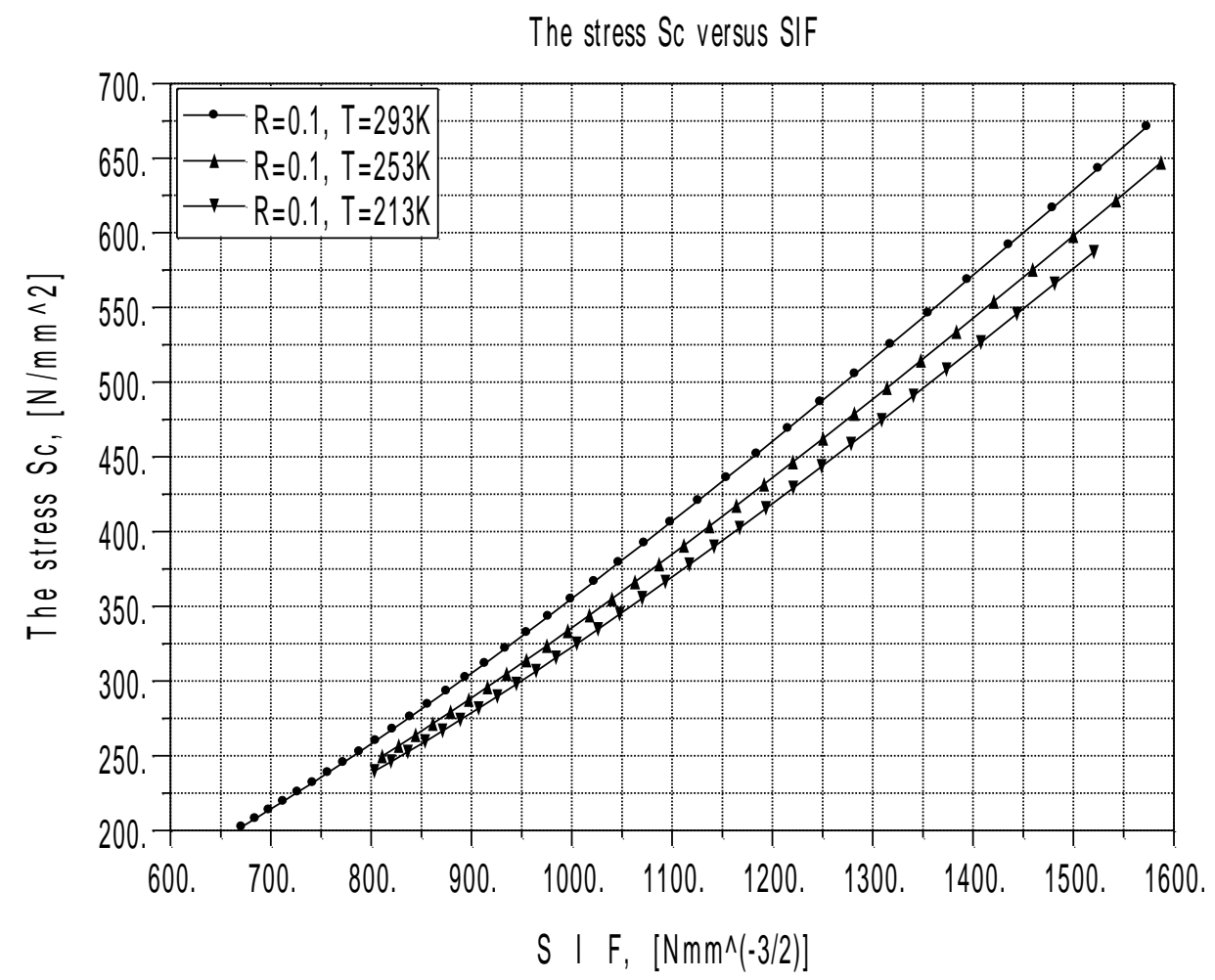

Figure 11: The stress Sc versus the stress intensity factor

\section{References}

1. Constantinescu, D.M., Structural integrity, University "Politehnica" Bucharest, (1998).

2. Dumitru, I., The basis of fatigue calculus, Eurostampa Publishing, Timisoara, (2009)

3. Mc Henry, H., I., A compliance method for crack growth studied at elevated temperatures, Journal ol Materials, 6 (4), pp. 862-873, (1971).

4. Pană, T., Pastramă, St., D., Mechanicals structures integrity, Fair Partners Publishing House, Bucharest, (2000)

5. Roşca, V., Contributions to the mono-axial fatigue study at low temperatures, Phd. Thesis, University Politehnica of Bucharest, (1997)

6. Roşca, V., The theory of elasticity applied in Strength of Materials, Curtea Veche Publishing, Bucureşti, (1997).

7. Roşca, V., The modelling of mechanical structures fracture, Universitaria Publishing, Craiova, (2008).

8. Rusu, O., Teodorescu, M., Laşcu-Simion, N., Materials fatigue, vol. 1 - Calculus basis, vol. 2 - Engineering applications, Technical Publishing House, Bucharest (1992).

9. ASTM E647-95, Standard Test Method for Measurement of Fatigue Crack Growth Rates, American National Standard.

10. Roşca, V., The variation of stress at the spike of the crack into an unoxidable steel submitted to tiredness at the temperature of $213 \mathrm{~K}$, "The $10^{\text {th }}$ International Symposium on Experimental Stress Analysis and Material Testing", Vol. 1, 1-33 - 1-36, Sibiu, Romania, 21-23 October, (2004).

11. V. Roşca, C.M. Miriţoiu, The crack length gwroth - a fracture parameter in a stainless steel influenced by the temperature loading test, Applied Mechanics and Materials, 823, pp. 489-494, (2016). 